\title{
La obra de Enace, el epílogo de la vivienda social construida por el Estado
}

\author{
Franco Valentino Haymes López \\ Eduardo Francisco Peláez Cruz del Castillo
}

Universidad de Lima, Perú

Recibido: 29 de agosto del 2016 / Aprobado: 22 de diciembre del 2016

La vivienda social construida por el Estado ha sido un tema fundamental para la creación del cuerpo teórico de la arquitectura y urbanismo en el Perú. No obstante, los estudios realizados parecen soslayar el último periodo en el que el Estado desempeñaba un papel protagónico en la planificación, ejecución y promoción de la vivienda de bajo costo. Nos referimos, a la obra construida por la Empresa Nacional de Edificaciones (Enace) durante la década de 1980, especialmente a lo realizado en su primer lustro, durante el segundo gobierno de Belaunde. El entendimiento de sus orígenes, las herramientas creadas para favorecer la construcción de vivienda social y su financiamiento, la variedad tipológica, la escala de su producción, así como el impacto de sus proyectos en la ciudad de Lima son los temas por analizar.

Enace, vivienda social, políticas de vivienda, vivienda y Estado

\section{Enace's Work, the Epilogue of the Social Housing Built by the State}

The social housing built by the Government has been a fundamental issue for creating the theoretical body of architecture and urbanism in Peru. However, the studies made seem to avoid the period when the State had the lead role in the planning, realization and promotion of the low cost housing. We refer to the work built by the State building company (Enace) during the 80's, especially to the work done during its first five years, during the second administration of president Belaunde. Understanding its origins, the tools created to favor the construction of social housing and its finance, the typological variety, its production scale, as well as the impact of its projects in the city of Lima are issues to be analyzed.

Enace, social housing, housing policies, housing and State 


\section{INTRODUCCIÓN}

La relación entre el Estado peruano y la vivienda social moderna se manifiesta visiblemente a principios de la década de 1930. En ese periodo, el proceso de "modernización del Estado", iniciado en los años veinte producía en Lima una incipiente industrialización. El resultado: un incremento sustancial demográfico de la ciudad, concentración urbana, tugurización y hacinamiento en el centro de Lima. En ese contexto, la Beneficencia de Lima construyó los primeros barrios obreros destinados a sectores económicos bajos, y fue el arquitecto Alfredo Dammert el responsable de la mayoría de dichos proyectos. Los diseños partían de una racionalidad moderna funcionalista $y$ constructiva, a la vez que recreaban la tipología de callejón o quinta ya existentes. Este tipo de arquitectura sería conocido posteriormente, de manera local, como de estilo buque.

Sin embargo, no se asumió el problema nacional de la vivienda con políticas de Estado sino hasta mediados de la década de los cuarenta. De hecho, el censo de 1940, realizado después del terremoto de Lima y Callao de ese año, ratifica las penosas condiciones de la vivienda en la ciudad (solamente una tercera parte del parque inmobiliario quedó en condiciones habitables).

Esa década fue especialmente rica en aportes $\mathrm{y}$ visiones renovadoras tanto para la vivienda de interés social como, en general, para la arquitectura y el urbanismo. En tal sentido, la figura del arquitecto Fernando Belaunde es trascendental. Por un lado, difundió por medio de su revista El Arquitecto Peruano los ideales modernos de una nueva arquitectura y urbanismo; y desde su posición como diputado de Lima, en el gobierno de Bustamante y Rivero, promovió iniciativas legales en pro de la planificación urbana de la ciudad, así como la creación de distintas instituciones en favor de esta, entre ellas la Corporación Nacional de la Vivienda (CNV) en 1946.

Se ha dicho que el gran aporte de la arquitectura peruana moderna es el concepto de las "unidades vecinales" (Kahatt, 2015). Estas recogen y fusionan la experiencia de los Greenbelt y de la política del New Deal norteamericano, las teorías de Perry sobre la neighborhood unit, así como los grands ensembles franceses de la tradición europea. Es precisamente la CNV la que impulsaría la construcción de la primera de ellas: la unidad vecinal n. ${ }^{\circ} 3$ (UV3) en 1949.

La UV3, con sus 1115 viviendas, nace de la necesidad imperiosa de descongestionar el centro, ya para entonces tugurizado, y de construir complejos habitacionales que brindaran una variada tipología de viviendas, además de servicios comunales que garantizaran su independencia del resto de la ciudad. Proyectos similares se construirán después, en la década de los cincuenta, en Matute, Mirones y El Rímac.

Otros proyectos de vivienda promovidos por la CNV son los agrupamientos Angamos, Miraflores, Risso, Alexander, San Eugenio o Barboncito. A diferencia de las unidades vecinales, estos no estaban destinados a la clase obrera, sino a una población de mayores recursos económicos. Difieren también en la escala, el número de viviendas en estos proyectos oscilaba entre las 90 y las 140 unidades. Además, carecían de comercio o equipamiento, por lo que se infiere que no estaban pensados para ser fragmentos autónomos en su funcionamiento, sino más bien tenían la intención de integrarse al tejido urbano adyacente.

En el gobierno de Manuel Prado se crea la Comisión Nacional para la Reforma Agraria 
y Vivienda (CRAV), la cual buscaba aplicar "soluciones viables" al problema de la vivienda informal que se originó con el incremento sustancial de invasiones y barriadas desde inicios de los cincuenta. Con dicho fin, se promulga en febrero de 1961 la Ley 13517 de Remodelación, Saneamiento y Legalización de Barrios Marginales, con la que se crearon las urbanizaciones populares de interés social (UPIS). Destacan los casos de Pamplona Baja, Condevilla yValdivieso que en conjunto suman 6750 núcleos básicos; así como el de El Agustino con 500 casas terminadas.

Un año antes de que Belaunde llegara a la presidencia, en 1962, la CNV y la CRAV se asocian y nace la Junta Nacional de Vivienda (JNV).A partir de entonces, la JNV se encargará de intentar dar solución a los problemas de vivienda. Como política estatal, durante el primer gobierno de Belaunde, se dejó de lado el trabajo alcanzado con la Ley 13517 y se priorizó la construcción de viviendas terminadas para la clase media del país.

Entre los proyectos impulsados por la JNV destaca la Residencial San Felipe. Este proyecto de 1600 unidades de vivienda fue diseñado por el arquitecto Enrique Ciriani y el arquitecto Mario Bernuy en la primera etapa, y por los arquitectos Víctor Smirnoff, Jorge Páez, Luis Vásquez, entre otros, en etapas posteriores. A diferencia de los proyectos anteriores a este en materia de vivienda social, en la Residencial San Felipe, aun cuando hay una variada tipología de vivienda, se apuesta principalmente por la vivienda en altura, en edificios que superan los diez pisos. Estos bloques de vivienda se organizan e integran, no por medio de plazas, patios, ni calles, sino con la idea de ser una gran área verde unificadora en la que se insertan los edificios.
Otros proyectos que ejecuta la JNV son el conjunto habitacional Palomino, diseñado por los arquitectos Luis Miró Quesada, Santiago Augurto, Fernando Correa y Alfredo Sánchez Griñán, con 1675 unidades de vivienda; y el conjunto residencial Santa Cruz, que inaugura la tipología de vivienda dúplex en los conjuntos habitacionales construidos por el Estado.Mención especial merece el Proyecto Experimental de Vivienda (PREVI), que fue encargado en las postrimerías del gobierno de Belaunde y ejecutado por el gobierno de las Fuerzas Armadas que le sucedió. Este proyecto fue promovido por el Estado y por el Programa de Naciones Unidas para el Desarrollo, y fue sometido a concurso internacional, a fin de desarrollar nuevos prototipos de vivienda que siguieran los conceptos de racionalización, modulación, tipificación y crecimiento progresivo.

No obstante, durante el gobierno militar de la década de los setenta, se tuvo una actitud más receptiva con los más pobres y se iniciaron programas de lotización básica y demás (aunque puede ser también entendido como una estrategia política clientelista). Destaca el caso de Villa El Salvador como ejemplo paradigmático de la barriada planificada. Así mismo, se creó el Ministerio de Vivienda (bajo Ley Orgánica 17528) y el Fondo Nacional deVivienda (Fonavi).

\section{LA OBRA DE ENACE EN CONTEXTO}

En 1980, tras el gobierno militar de Velasco Alvarado y Morales Bermúdez, Belaunde alcanza la presidencia del Perú. Es precisamente en la década de los ochenta cuando se agudizan los problemas de inmigración en todo el país y empiezan a extenderse las ciudades con las invasiones y las barriadas, se tugurizan y 
deterioran algunas ciudades y aumenta el déficit habitacional. En tanto que, en el ámbito internacional, la corriente neoliberal conquista los modelos económicos y políticos de las grandes potencias, la intervención del Estado, bajo ese sistema, apunta a ser mínima y deja a "la mano invisible" de la economía regular la inversión privada.

Es en este contexto que, en junio de 1981, bajo Decreto Legislativo N. ${ }^{\circ} 149$, se creó la Empresa Nacional de Edificaciones (Enace). Esta entidad fue concebida como una empresa de propiedad del Estado, ágil y eficiente, que busca la promoción, la planificación, el financiamiento, la proyección, la ejecución y la adjunción de programas de habilitación urbana, la construcción de viviendas y los servicios complementarios referentes a los Programas Habitacionales del Plan Nacional de Vivienda (PNV) 1980-1985 formulados a inicios del gobierno de Belaunde.

Dada la coyuntura de explosión urbana informal en muchas de las ciudades del país (sea a causa de la aparición del terrorismo en las provincias o como consecuencia de la reforma agraria), el PNV se planteó como objetivo otorgar viviendas a más pobladores que en gobiernos anteriores y de manera más descentralizada. Por ello Enace se organizó por unidades operativas según el territorio donde se desempeñase y la magnitud de los proyectos. En el norte del país, se activaron las unidades operativas de Piura y Trujillo. La unidad operativa central cubría los territorios de Ica, Lima (exclusivamente las provincias de Cañete y Yauyos), Ayacucho, Junín, Pasco y Huánuco; y contaba además con una oficina de supervisión para las regiones orientales del país. El sur del país tenía, a su vez, dos unidades operativas, la del Cusco y la de Arequipa.

El caso de la capital era particular. La Unidad Operativa Lima estaba destinada a trabajar exclusivamente para Lima Metropolitana, debido a que en ella se concentraba un caos urbano y carencia de viviendas superior al resto de ciudades. Existían además unidades operativas independientes, debido a la complejidad y a la escala de los proyectos en cuestión; estas eran las siguientes: la Unidad Operativa San Borja para los proyectos Torres de San Borja y Julio C. Tello; la Unidad Operativa Limatambo para el proyecto Torres de Limatambo y la Unidad Operativa Santa Rosa para el proyecto Ciudad Satélite de Santa Rosa. 
Tabla 1. Unidades operativas de Enace en el departamento de Lima

\section{Unidad operativa Lima}

\begin{tabular}{|c|c|c|c|c|c|c|}
\hline Ubicación & Proyecto & Tipo & $\begin{array}{c}\text { Área } \\
\text { terreno }\end{array}$ & Unidades & Equipamiento & Arquitecto \\
\hline $\begin{array}{l}\text { Lima } \\
\text { (Surquillo) }\end{array}$ & $\begin{array}{l}\text { Alfredo } \\
\text { Dammert } \\
\text { Muelle }\end{array}$ & Multifamiliar & 3,12 ha & 452 & $1 \mathrm{CEI} / 1 \mathrm{EC}$ & $\begin{array}{c}\text { P. Busos, F. Gomero, } \\
\text { C. Pastor }\end{array}$ \\
\hline $\begin{array}{c}\text { Lima } \\
\text { (Magdalena } \\
\text { del Mar) }\end{array}$ & Marbella & Multifamiliar & 3,19 ha & 300 & $1 \mathrm{CEl} / 6 \mathrm{~T}$ & C. Ausejo \\
\hline $\begin{array}{c}\text { Lima } \\
\text { (La Victoria) }\end{array}$ & $\begin{array}{l}\text { Nuesta Señora } \\
\text { de las Victorias }\end{array}$ & Mixto & 0,43 ha & $\begin{array}{c}111 \text { en } \\
\text { multifamiliar }+9 \\
\text { casas tienda }\end{array}$ & Plaza & $\begin{array}{l}\text { O. Núñez, } \\
\text { C. Williams }\end{array}$ \\
\hline $\begin{array}{l}\text { Lima } \\
\text { (Surco) }\end{array}$ & Precursores & Mixto & 23,23 ha & $\begin{array}{c}897 \text { unifamiliar + } \\
24 \text { multifamiliar }+ \\
10 \text { casas tienda }\end{array}$ & $\begin{array}{c}1 \text { CEl / } 1 \text { CEB / 16T / } \\
\text { parque infantil }\end{array}$ & $\begin{array}{l}\text { J. Baracco, R. Bentín, } \\
\text { A. Montagne, V. } \\
\text { Ramírez, V. Smirnoff }\end{array}$ \\
\hline $\begin{array}{l}\text { Lima } \\
\text { (Huacho) }\end{array}$ & $\begin{array}{c}\text { Domingo } \\
\text { Mandamiento } \\
\text { Sipán }\end{array}$ & Multifamiliar & $\begin{array}{l}\text { No hay } \\
\text { información }\end{array}$ & $\begin{array}{l}188 \text { multifamiliar } \\
+4 \text { dep. tienda }\end{array}$ & No hay información & S. Agurto Calvo \\
\hline $\begin{array}{l}\text { Lima (Cercado } \\
\text { de Lima) }\end{array}$ & $\begin{array}{l}\text { Julio Ponce } \\
\text { Antúnez de } \\
\text { Mayolo }\end{array}$ & Multifamiliar & 0,41 ha & 130 & No hay información & $\begin{array}{c}\text { G. Costa, } \\
\text { L. Santisteban }\end{array}$ \\
\hline Lima (Zárate) & $\begin{array}{c}\text { Enrique } \\
\text { Seoane Ros }\end{array}$ & Multifamiliar & 2,57 ha & 336 & No hay información & R. Madueño \\
\hline Lima (Comas) & Los Chasquis & $\begin{array}{l}\text { Núcleos } \\
\text { básicos }\end{array}$ & 5,44 ha & 344 & 1 CEB / 1 CEl & Ing. E. Villarán \\
\hline Lima (Comas) & Los Amautas & Unifamiliar & 13,59 ha & 345 & $1 \mathrm{CEl} / \mathrm{OU}$ & R. Madueño \\
\hline $\begin{array}{c}\text { Lima } \\
\text { (Chancay) }\end{array}$ & $\begin{array}{l}\text { Andrés de los } \\
\text { Reyes Buitrón }\end{array}$ & Unifamiliar & 1,95 ha & 95 & $1 \mathrm{CEI} / \mathrm{LOU}$ & O. Tang Pou Sang \\
\hline $\begin{array}{c}\text { Lima } \\
\text { (San Martín } \\
\text { de Porres) }\end{array}$ & $\begin{array}{l}\text { Carlos Cueto } \\
\text { Fernandini }\end{array}$ & Mixto & 26,73 ha & $\begin{array}{l}1087 \text { núcleos } \\
\text { básicos }+4 \\
\text { unifamiliar }\end{array}$ & $\begin{array}{l}1 \text { CEB / } 2 \text { CEl / (por construir: } \\
\text { C. Sect/ merc. / C. Salud / } \\
\text { GC/PIP/correo / CT/I/CC) }\end{array}$ & $\begin{array}{l}\text { O. Chaparro, } \\
\text { M. Asurza }\end{array}$ \\
\hline $\begin{array}{l}\text { Lima (Villa } \\
\text { El Salvador) }\end{array}$ & $\begin{array}{l}\text { Agrupamiento } \\
\text { Pachacámac }\end{array}$ & Mixto & 283,72 ha & $\begin{array}{c}7069 \text { ejecutados } \\
\text { (3116 núcleos } \\
\text { básicos }+3953 \\
\text { lotes con servicios) } \\
+7172 \text { por } \\
\text { ejecutar }\end{array}$ & $\begin{array}{l}21 \text { CEI ( } 2 \text { constr.) / } 3 \text { CEB (1 } \\
\text { constr.) / } 6 \text { casa c. / } 3 \text { T_CP / } \\
3 \text { C. salud ( } 1 \text { constr.) / } 3 \text { of. c } \\
\text { / } 2 \text { CT / } 3 \text { bib. / } 3 \text { C_PNP / } 9 \\
\text { loc. } \text { / } 2 \text { inst.. }\end{array}$ & $\begin{array}{l}\text { M. Asurza, V. Ridout, } \\
\text { H. Ruibal, M. Bernuy, } \\
\text { T. Vega, T. García, } \\
\text { C. Pastor }\end{array}$ \\
\hline $\begin{array}{l}\text { Lima } \\
\text { (San Juan de } \\
\text { Lurigancho) }\end{array}$ & $\begin{array}{l}\text { Ciudad de los } \\
\text { Constructores }\end{array}$ & $\begin{array}{l}\text { Lote con } \\
\text { servicios }\end{array}$ & 350,00 ha & $\begin{array}{c}9233 \text { ejecutados } \\
+14201 \text { por } \\
\text { ejecutar }\end{array}$ & $\begin{array}{c}1 \text { ESEP / } 10 \text { CEB /55 CEI/ } \\
1 \text { hosp. gen. /3 C. salud } \\
\text { / } 1 \text { Com. PIP / } 1 \text { C. GC /3 } \\
\text { Comis. PIP / } 3 \text { C. GC / } 1 \text { C. } \\
\text { bomb. / } 1 \text { sub. CC / } 3 \text { of. } \\
\text { correos / } 1 \text { of. E / } 3 \text { CT / } 3 \\
\text { Bib. / } 3 \text { C. dist. / } 3 \text { merc. / } \\
9 \text { casas c. / } 9 \text { T / } 1 \text { P. Vea } \\
\text { / } 2 \text { parq. zonales / } 13 \\
\text { plazuelas }\end{array}$ & $\begin{array}{c}\text { Enrique Alegre, } \\
\text { Juan Sierra }\end{array}$ \\
\hline $\begin{array}{c}\text { Callao } \\
\text { (Ventanilla) }\end{array}$ & $\begin{array}{l}\text { Ciudad del } \\
\text { Deporte }\end{array}$ & Mixto & 28,18 ha & $\begin{array}{c}4259 \text { (unifamiliar } \\
+ \text { multifamiliar) }\end{array}$ & $\begin{array}{l}\text { Información por } \\
\text { confirmar }\end{array}$ & $\begin{array}{c}\text { J. Bentín, } \\
\text { A. Montagne, } \\
\text { A. Ortiz de Zevallos }\end{array}$ \\
\hline
\end{tabular}


(continuación)

Unidad operativa Limatambo

\begin{tabular}{|c|c|c|c|c|c|c|}
\hline Ubicación & Proyecto & Tipo & Área terreno & Unidades & Equipamiento & Arquitecto \\
\hline $\begin{array}{l}\text { Lima } \\
\text { (San Borja) }\end{array}$ & $\begin{array}{c}\text { Torres de } \\
\text { Limatambo }\end{array}$ & Multifamiliar & 27,94 ha & $\begin{array}{c}2316 \\
\text { ejecutados } \\
+544 \text { por } \\
\text { ejecutar }\end{array}$ & $\begin{array}{l}\text { *1 CEB / } 4 \text { CEl } \\
\text { / } 1 \text { I / } 1 \text { equip. } \\
\text { comu. / }{ }^{*} \text { C. com. } \\
\text { / } 167 \text { tiendas / } 95 \\
\text { of. / } 64 \text { tiendas } \\
\text { / } 1 \text { coliseo / } 1 \text { c. } \\
\text { depor. / } 1 \text { parque }\end{array}$ & $\begin{array}{l}\text { O. Barsino, } \\
\text { M. Ferreyra, } \\
\text { J. Gutiérrez, } \\
\text { D. La Rosa, } \\
\text { R. Ledgard, } \\
\text { H. Romero }\end{array}$ \\
\hline
\end{tabular}

\section{Unidad operativa Santa Rosa}

\begin{tabular}{|c|c|c|c|c|c|c|}
\hline Ubicación & Proyecto & Tipo & Área terreno & Unidades & Equipamiento & Arquitecto \\
\hline $\begin{array}{c}\text { Callao } \\
\text { (Carmen } \\
\text { de la Legua) }\end{array}$ & $\begin{array}{l}\text { Ciudad Satélite } \\
\text { Santa Rosa }\end{array}$ & Multifamiliar & 50,89 ha & $\begin{array}{c}4056 \\
\text { multifamiliar }\end{array}$ & $\begin{array}{c}1 \text { CEB / } 4 \text { CEl /*3 } \\
\text { CEl / *1 c. . com. } \\
\text { / } 1 \text { m. min. / } 280 \\
\text { tiendas / } 46 \text { t. dep. } \\
\text { / } 1 \text { c. parroquial / } \\
* 1 \text { hospital /*1 c. } \\
\text { comunal }\end{array}$ & $\begin{array}{l}\text { O. Barsino, } \\
\text { M. Ferreyra, } \\
\text { J. Gutiérrez, } \\
\text { D. La Rosa, } \\
\text { R. Ledgard, } \\
\text { H. Romero }\end{array}$ \\
\hline
\end{tabular}

Unidad operativa San Borja

\begin{tabular}{|c|c|c|c|c|c|c|}
\hline Ubicación & Proyecto & Tipo & $\begin{array}{c}\text { Área } \\
\text { terreno }\end{array}$ & Unidades & Equipamiento & Arquitecto \\
\hline $\begin{array}{l}\text { Lima } \\
\text { (San Borja) }\end{array}$ & $\begin{array}{c}\text { Torres de San } \\
\text { Borja }\end{array}$ & Mixto & 30.80 ha & $\begin{array}{c}2218 \\
\text { multifamiliar } \\
187 \text { unifamiliar }\end{array}$ & $\begin{array}{c}\text { *1 CEB / } 2 \\
\text { cunas jardín / } 2 \\
\text { CEI / *2 C. . com. } \\
\text { / } 55 \text { tiendas }\end{array}$ & $\begin{array}{c}\text { G. Costa, J. Aragón, } \\
\text { C. Honores, A. Ochoa, } \\
\text { M. Llanos, M. Bernuy, } \\
\text { R. Chang, } \\
\text { O. Velásquez, } \\
\text { J. Canales, } \\
\text { J. Kanashiro, } \\
\text { C. Williams, } \\
\text { J. Bendezú, C. Salas, } \\
\text { P. Bustos, } \\
\text { F. Gomero, A. Molinari, } \\
\text { C. Pastor, E. Rojas, } \\
\text { O. Fernández, } \\
\text { W. Olivas, E. Tafur }\end{array}$ \\
\hline
\end{tabular}

Elaboración propia. Información basada en el libro Revolución habitacional en democracia: plan de vivienda del gobierno peruano 1980-1985, de Enace, Lima: Ministerio de Vivienda, 1985 


\section{SOBRE SUS INSTRUMENTOS Y ACCESO}

Solía decir Belaunde:"A cada organización de los hombres corresponde una organización paralela de las cosas" (Enace, 1985). Por ello, con el fin de poder ejecutar el PNV, Enace se apoyó en distintos instrumentos: el Fonavi, heredado del gobierno militar, suponía un fondo de solidaridad que favoreciera la construcción de viviendas y la habilitación de terrenos para estas; este sistema de recaudación se basaba en la contribución obligatoria de un porcentaje mínimo de los salarios de los trabajadores en planilla y de sus empleadores. El sistema de hipoteca social, que ofrecía créditos hipotecarios con una tasa de interés menor a la comercial vigente. El Banco de Materiales (Banmat) destinado a que los autoconstructores, que representaban un gran sector del desarrollo urbano informal, adquirieran materiales de calidad, así como asesoría técnica profesional.Y, finalmente, el Banco de laVivienda que administró eficientemente el sistema de hipoteca social.

A los bienes ofrecidos por Enace, en cualquiera de sus variedades, desde lotes tizados hasta viviendas multifamiliares, se accedía por concurso público y los trabajadores que estuviesen aportando al Fonavi, por lo menos tres años, podían postular a uno de ellos. Los postulantes debían elegir solo un tipo de vivienda determinada, por ejemplo: un departamento en el tercer piso, con dos dormitorios y vista al parque en Ciudad Satélite Santa Rosa. No obstante, al mismo tiempo, podían postular a otro tipo de vivienda en los demás proyectos de Enace (Limatambo o San Borja, por señalar algunos de los proyectos ejecutados en la ciudad de Lima).

\section{LOS PROYECTOS DE ENACE}

Se promovieron cinco tipos de proyectos: complejos habitacionales de viviendas de tipo unifamiliar, departamentos en edificios multifamiliares de mediana y gran altura para la clase media, proyectos de lotes, lotes con servicios y núcleos básicos para el sector de la población con menos recursos. Asimismo, Enace proyectó un total de 2550 lotes tizados para viviendas. En ellos se contemplaba no solo el espacio para las viviendas en sí mismas, sino también las áreas donde se construiría equipamientos para educación, comercio, seguridad y salud. El proyecto más grande ejecutado con lotes fue el de La Campiña, en Arequipa.

Con respecto a los proyectos de lotes y servicios (que contemplaban las instalaciones eléctricas, así como las de agua y desagüe) se ejecutaron un total de 28319 unidades, siendo el proyecto Ciudad de los Constructores, en Lima, el más ambicioso de ellos. Contaba con un total de 23434 unidades; 9233 de ellas ejecutadas y el resto por ejecutar; y fue concebido a partir de un esquema de lotización típico, en el que cada sector compuesto por doce manzanas necesitaba un equipamiento urbano mínimo. La suma de todos ellos debería haber garantizado la autonomía del proyecto. 


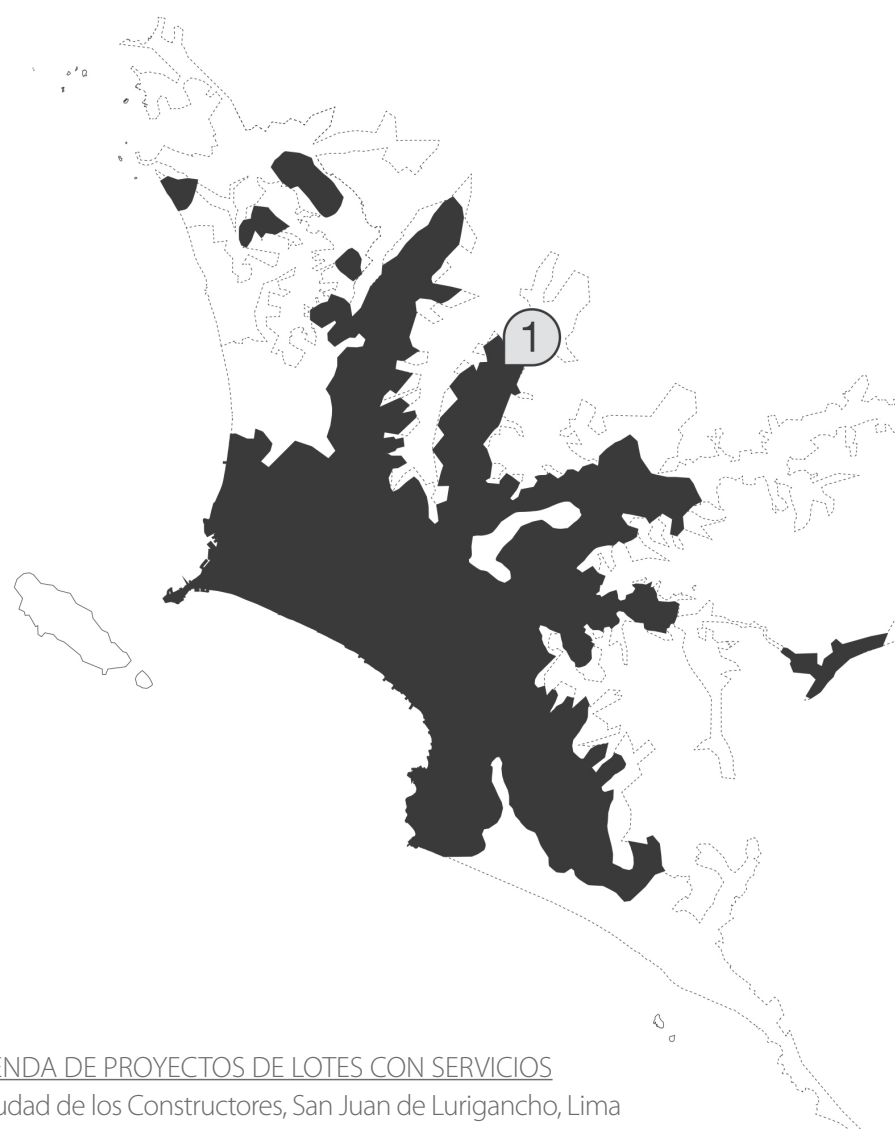

1. Ciudad de los Constructores, San Juan de Lurigancho, Lima

LEYENDA

Lima 1980

Lima 2016

Figura 1

Plano de Lima de 1980 con la ubicación del proyecto de lotes y

servicios desarrollado por Enace en Lima Metropolitana

Se construyeron también proyectos del tipo núcleo básico que, además de los servicios de luz, agua y desaguie, contaban con un ambiente de uso múltiple y un baño completo. El propietario, apoyándose en la autoconstrucción, culminaría su vivienda según sus necesidades particulares. En total fueron 1738 viviendas ejecutadas. 


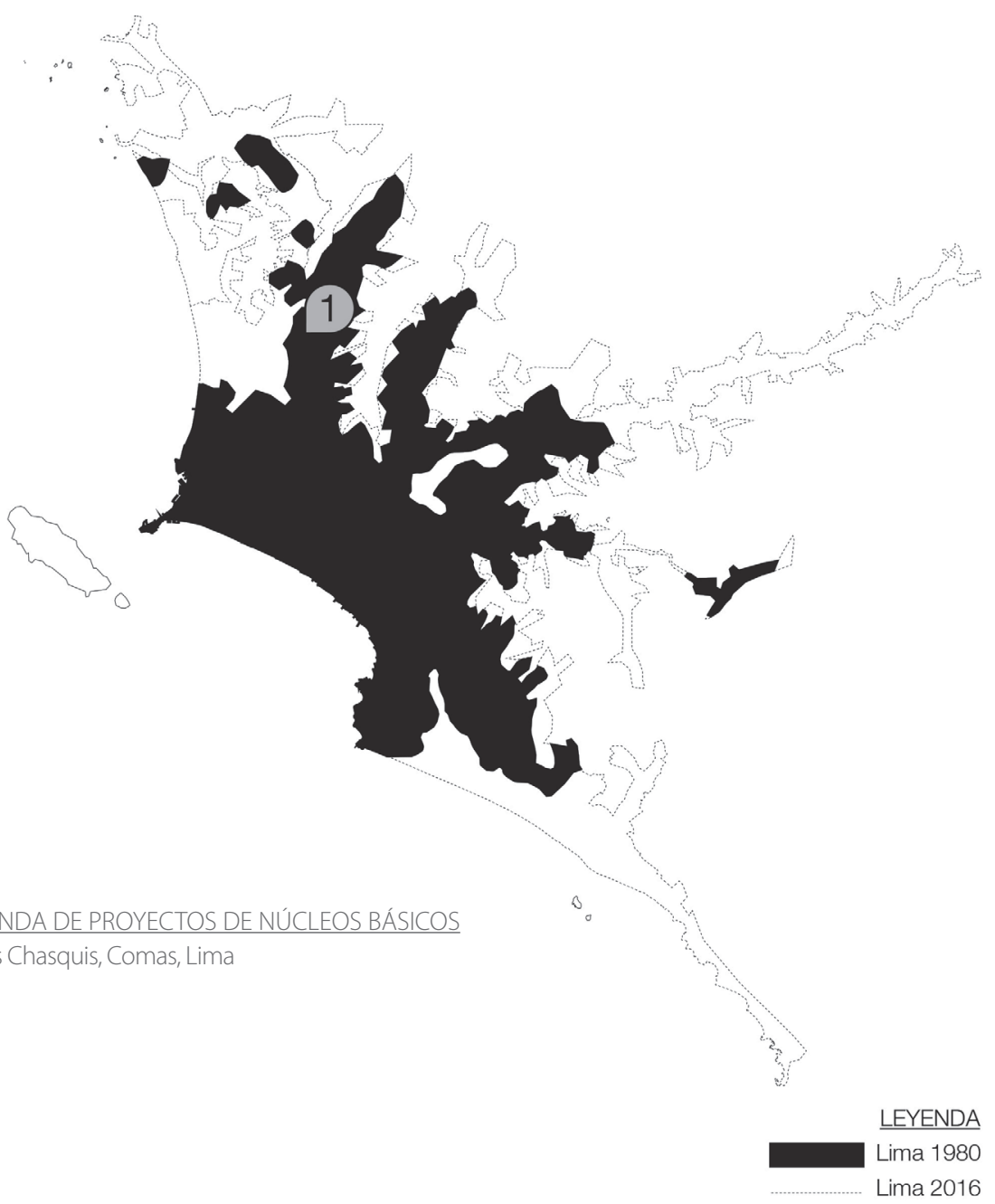

Figura 2

Base referente: Enace (1985). Revolución habitacional en democracia. Plan de vivienda del gobierno peruano 1980-1985. Lima: Ministerio de Vivienda Elaboración: Franco Haymes y Eduardo Peláez 


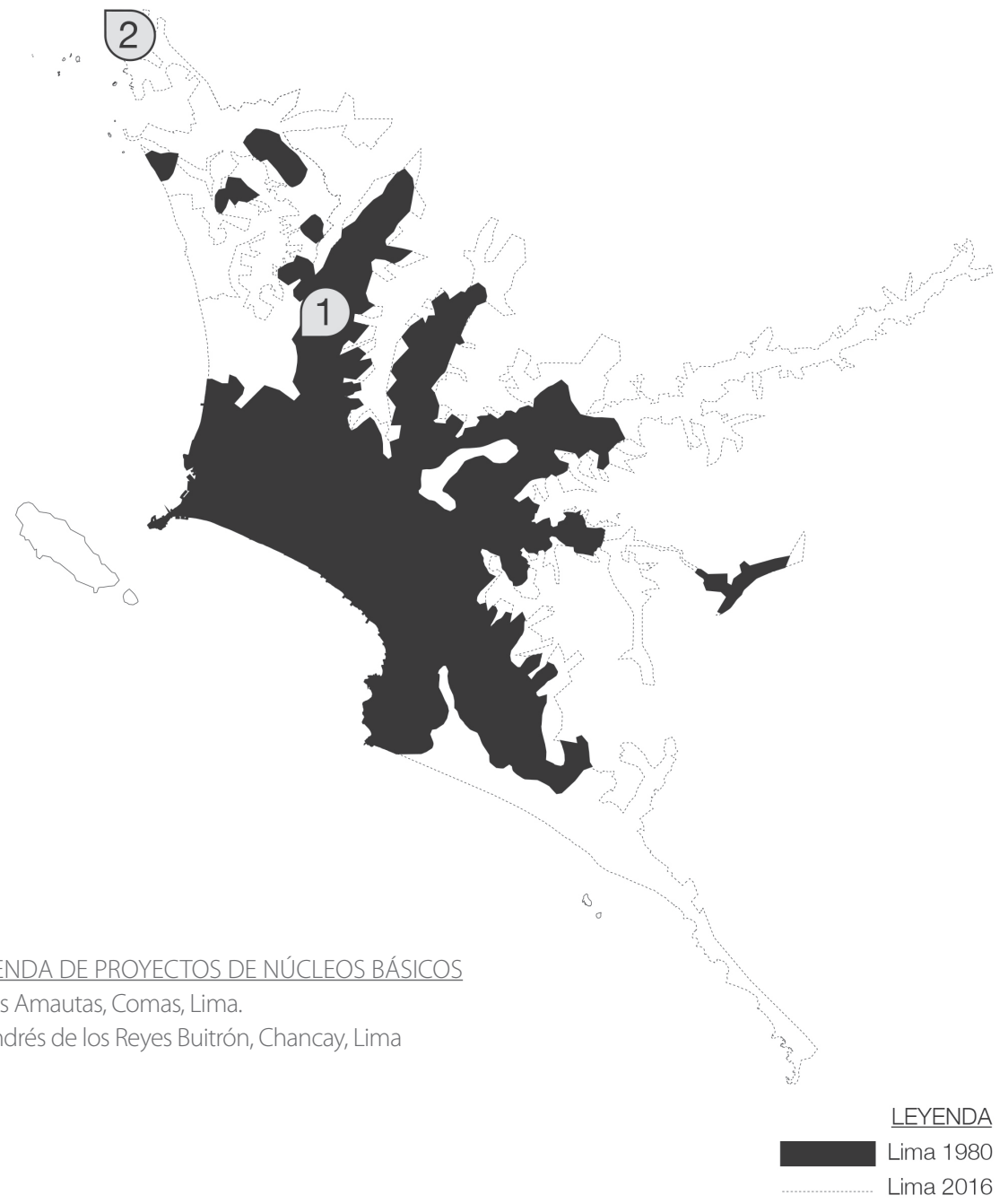

Figura 3

Plano de Lima de 1980 con la ubicación del proyecto del tipo núcleo básico desarrollado por Enace en Lima Metropolitana

Los proyectos destinados a la clase obrera media pertenecían al tipo unifamiliar y multifamiliar. Los proyectos exclusivamente de unifamiliares sumaron 1821 y su tipología en todos los casos eran bastantes similares. Proyectos que no superaban las 150 unidades del tipo chalet. Se entregaba un primer piso construido, teniendo en cuenta un crecimiento previsto de hasta tres niveles. 


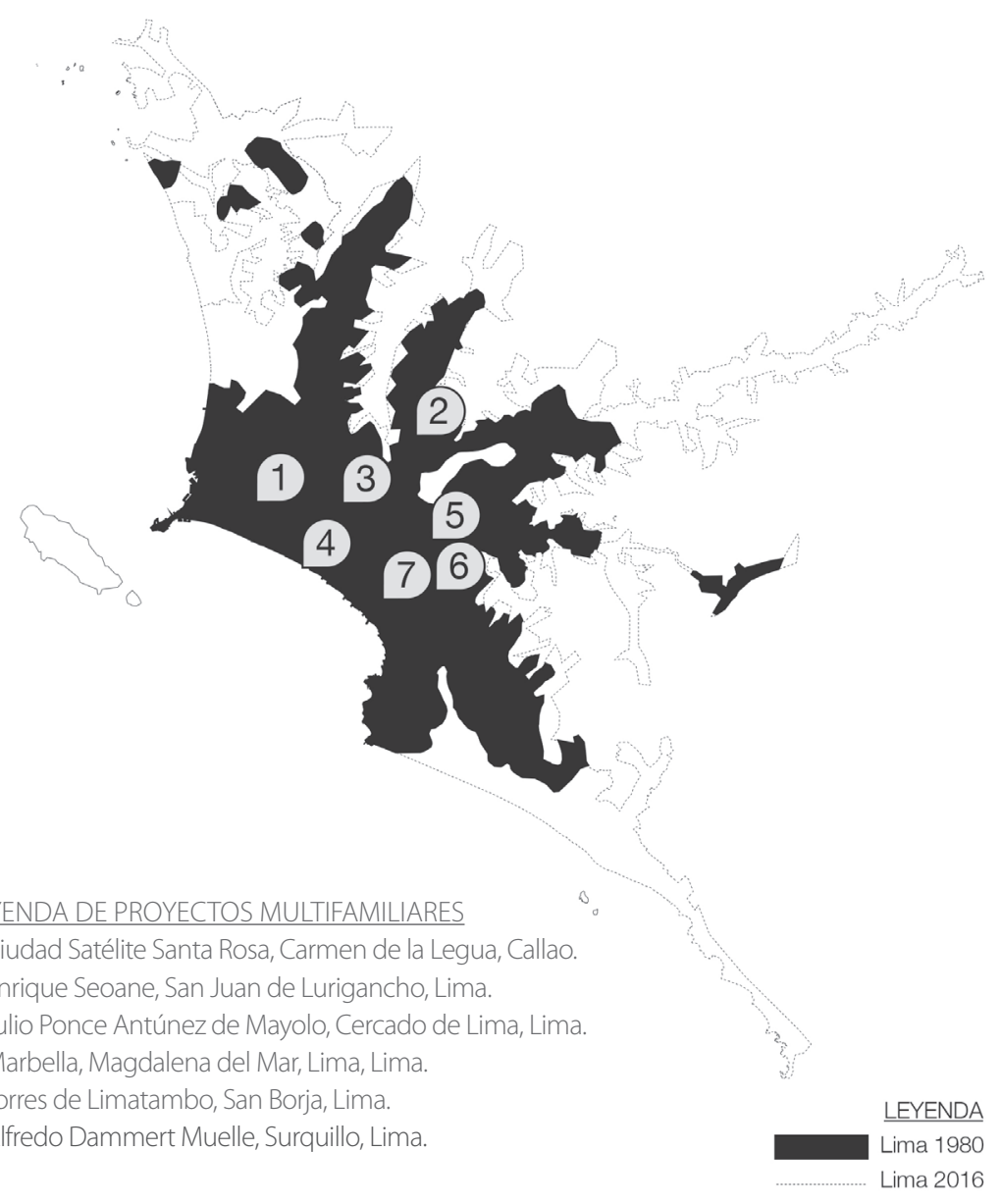

Figura 4

Plano de Lima de 1980 con la ubicación del proyecto de unifamiliares desarrollado por Enace en Lima Metropolitana

El caso de los proyectos de vivienda multifamiliar produjo el mayor número de viviendas construidas. Un total de 16025 departamentos en 21 complejos habitacionales. El diseño se basaba, generalmente, en dos o tres tipos de viviendas que formaban bloques.

Estos bloques tenían en su mayoría una expresión arquitectónica muy parecida entre sí, incluso entre proyectos. La altura mínima de estos multifamiliares era de tres pisos y la máxima, de cinco. Se organizaban de tal manera que un número de bloques determinado generaba un espacio público de una escala barrial; mientras que su organización conjunta daba lugar a espacios de mayor dimensión. 


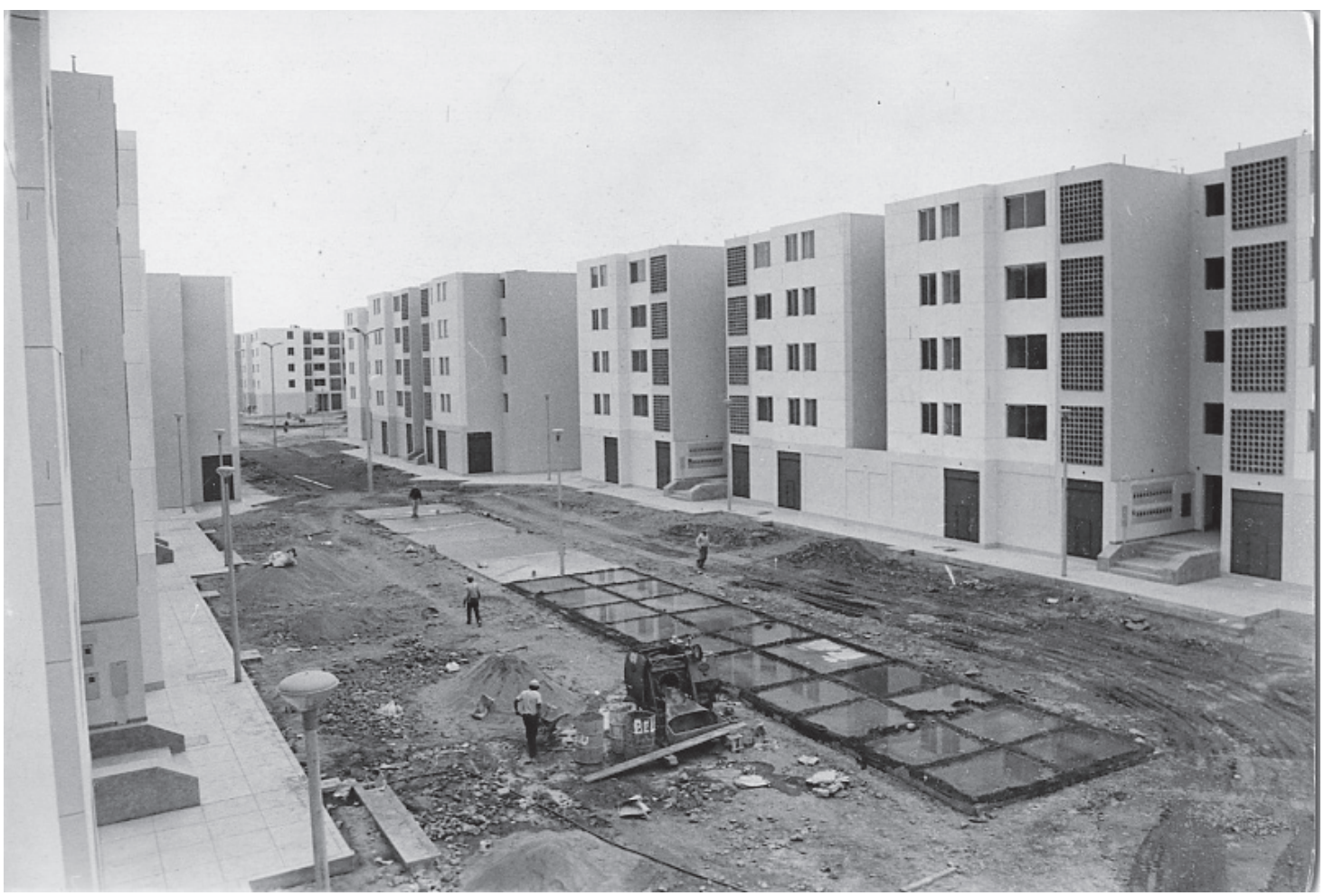

Figura 5

Imagen de la construcción de la Ciudad Satélite Santa Rosa realizada por Enace.

Fuente: http://repositorio.usil.edu.pe/handle/123456789/497

Finalmente, dentro de la obra de Enace también existieron proyectos mixtos. No obstante, generalmente se fusionaban los lotes con servicios y núcleos básicos, como fue el caso del proyecto Urbanización Ignacio Merino en Piura con 1561 viviendas, o los de vivienda terminada con unifamiliares y multifamiliares, como pasó con el conjunto residencial Torres de San Borja con sus 2405 viviendas.

Se estima que durante el gobierno de Belaunde y bajo la dirección de Enace se produjeron, entre lotes y viviendas terminadas, 76466 unidades de vivienda, siendo este el periodo más prolífico y descentralizado en materia de vivienda social. 


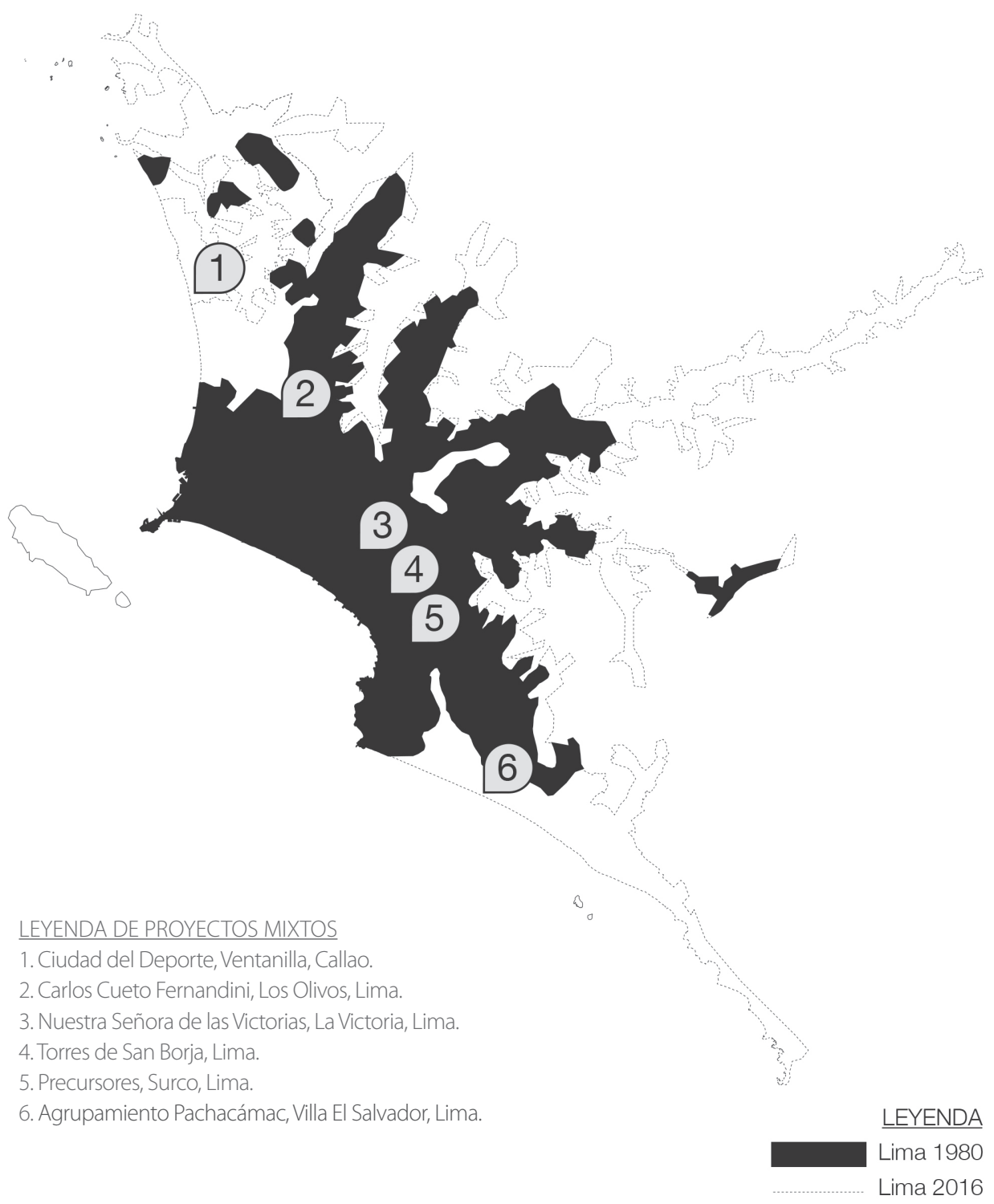

Figura 6

Plano de Lima de 1980 con la ubicación de proyectos mixtos desarrollados por Enace en Lima Metropolitana 


\section{CONCLUSIONES}

Enace fue una institución Estatal creada en la década de los ochenta que marcó un último hito en el compromiso del Estado en la promoción, planificación, ejecución y construcción de viviendas, habilitación urbana y equipamiento públicos complementarios a nivel nacional. Los distintos tipos de proyectos realizados por Enace evidenciaban un compromiso por consolidar y densificar entornos donde la ciudad ya se había consolidado; y también por crear nuevas ciudades en los bordes de Lima Metropolitana propiciando el crecimiento gradual y progresivo de la vivienda autoconstruida, así como la extensión de la ciudad en sentido horizontal.

La mayoría de las obras construidas por Enace presentan una relación programática y estéticamente moderna, símbolo de la arquitectura del primer gobierno de Belaúnde. Ejemplos de ello pueden ser la Ciudad Satélite de Santa Rosa, Julio C. Tello, Marbella, entre otros, que están constituidos por piezas únicas que se van organizando para propiciar espacio público, plazas y generar así un vínculo entre la vivienda y la ciudad. Sin embargo, también aparecieron proyectos innovadores en su época con nuevas estrategias de emplazamiento, circulación y construcción, como Próceres y Limatambo. Además de ser el proyecto de vivienda social más grande de Sudamérica en esos tiempos, Próceres significó un hito en la diferenciación de la circulación entre el peatón y el automóvil. Mientras que Limatambo sostuvo la idea del regionalismo crítico a partir del planteamiento de un trazado ortogonal histórico de Lima.

Enace, en la zona urbana de Lima de 1980, trabajó en dos zonas diferentes y respondió a dos formas de intervención distintas. Por un lado, se buscó densificar el centro urbano de Lima insertando proyectos multifamiliares con usos mixtos que ayudaban a reforzar territorios urbanos con mejor infraestructura residencial y de servicios. Por el otro, en vista de que no se había pensado en densificar hacia la periferia de la ciudad, se crearon pequeñas urbanizaciones horizontales con trazado de lotes que en el fondo reforzaban la idea de una ciudad difusa. $\mathrm{Y}$ aunque este tipo de habilitación urbana parecía basarse en un compromiso del Estado por brindar un formato accesible de vivienda a la población, no era un compromiso con la ciudad misma, ya que estos nuevos centros iban a ser los detonantes, tiempo más tarde, de la expansión difusa de Lima en esas direcciones.

Para inicios de la década de los noventa, durante el gobierno de Fujimori, el cambio de constitución dejó de reconocer a la vivienda como una necesidad básica de la persona y se restringió el concepto de políticas públicas (Quispe, 2005). A su vez, la desinstitucionalización del gobierno y la adopción de un modelo neoliberal, condenó a que el rol del Estado como planificador, constructor y promotor de la vivienda social/económica quedara relegado al de un instrumento facilitador de políticas a favor de la inversión privada y de bonos económicos de subsidio.

Es cierto que, con la caída de la dictadura a inicios del 2000, y la reinstauración/creación del Ministerio de Vivienda Construcción y Saneamiento en el 2002, se reencauza el interés por el problema de la vivienda. Signo de esto es la creación del programa (aún hoy vigente) Techo Propio, Mivivienda, entre otros. Muy a pesar de ello, al finalizar el periodo de Enace, no se observaría más el uso, por parte del Estado, de la vivienda social como un instrumento rehabilitador y democrático para la construcción de ciudad. 


\section{REFERENCIAS:}

Córdova, A. (2007). El Estado y el problema de la vivienda, 1945-2005. 50 años de vivienda en el Perú. Scribd. Recuperado de https:// es.scribd.com/document/251223169/50Anos-de-Vivienda-en-El-Peru

Enace (1985). Revolución habitacional en democracia. Plan de vivienda del gobierno peruano 1980-1985. Lima: Ministerio de Vivienda.

Kahatt, S. (2015). Utopías construidas: Las unidades vecinales de Lima. Lima: Pontificia Universidad Católica del Perú, Fondo Editorial.

Ledgard, R. (2015). La ciudad moderna. Textos sobre arquitectura peruana. Lima: Pontifica Universidad Católica del Perú, Fondo Editorial.
Ludeña, W. (1983). Las Torres de San Borja o el ocaso de la urbanística. Lima: Lluvia.

Ludeña, W. (2004). Lima: historia y urbanismo 1821-1970. Vol. I. Lima: Universidad Nacional de Ingeniería.

Martuccelli, E. (2000). Arquitectura para una ciudad fragmentada. Lima: Universidad Ricardo Palma.

Quispe, J., Arias T., y Maquet, P. (mayo del 2005). El problema de la vivienda en el Perú, retos y perspectivas. Revista INVI, 20(53), 20-44.

Santisteban, G. (2005). Análisis de políticas de vivienda de interés social (1980-2004), (tesis para optar el grado de maestro en ciencias) Lima: Universidad Nacional de Ingeniería. 
